\title{
Algal biofuel: the future of green jet fuel in air transportation
}

\begin{abstract}
The aviation industry is one of the major contributors for the greenhouse gases. As air travel has become inevitable in this modern era, and fossil fuel usage is not sustainable, it is essential to produce renewable fuel and commercialize it to reduce the greenhouse gas emissions. In order to produce an alternate aviation biofuel a lot of industrial and academic collaborations have been developed worldwide. The main concern of this collaborative research is to produce aviation biofuel from renewable resources with low environmental impacts, and which is sustainable at an economically viable price. This minireview briefly discusses the biotechnological approaches adapted to improve renewable fuel production, the current achievement with regard to algal biotechnology, and whether these biotechnological and bioengineering achievements can be commercialized today in the aviation industry.
\end{abstract}

Keywords: biofuel, microalgae, aviation biofuel, genetic engineering, metabolic engineering
Volume 5 Issue 2 - 2018

\author{
Olaganathan Rajee \\ Department of Math, Physical and Life Sciences, Embry-Riddle \\ Aeronautical University, USA
}

\begin{abstract}
Correspondence: Olaganathan Rajee, Department of Math, Physical and Life Sciences, Embry-Riddle Aeronautical University, 5930 S Sossaman Rd \#102, Mesa, AZ 852 I2, USA, Tel + I 626 236 2254, Email rajee.olaganathan@erau.edu
\end{abstract}

Received: November 01, 2017 | Published: April 16, 2018

\section{Introduction}

The demand for air travel is increasing drastically while airlines are spending millions of dollars (approximately 28\% of their operating cost) to fuel their fleets. ${ }^{1}$ The volatility of pricing within the aviation industry has created an awareness of the need for alternative fuels for commercial aircraft. 1,2 Apart from the volatility of oil prices, the aviation industry also faces challenges related to both the environment and toward energy availability. A lot of current research is aimed towards developing renewable biofuels as an alternative energy resource for air transportation. Compared to the first and second generation biofuels, the third-generation biofuel technology and techniques have ascertained that microalgae-derived fuels are the best alternative energy resource. ${ }^{3}$ The efficiency of algae to sequester carbon from the atmosphere, its ability to utilize the nutrients present in wastewater and industrial effluents, its non-competence with agricultural land, water resources, and food crops has made it a potential leading candidate for alternate fuel exploitation. ${ }^{4}$

\section{Biotechnology approaches}

During the last few years, the usefulness of biotechnology in various applications has been extensively developed. The biotechnological approaches adopted to improve renewable fuel production are classical mutation, and selection or plant breeding, which includes techniques for selecting the mutant strain that occurs in a natural habitat or by selectively breeding the different variety of strains or plants; directed evolution refers to the process in which the microbial strains are randomly grown under the optimum conditions, mutated under selective pressure and the over performing mutated strains are selected; recombinant DNA technology i.e., fragments of DNA from different species are combined together and inserted into a host organism (microorganism, algae, or plant) to develop a new strain to achieve the desired biochemical function; ${ }^{5}$ DNA shuffling is a directed evolution that uses different techniques to connect the genes in a variety of combinations, mutate the gene that encodes the enzyme for desired improvements, and after the beneficial mutation the high performing strains are selected. ${ }^{5}$ Metabolic engineering uses the technologies of recombinant DNA to either alter or enhance the existing metabolic pathways, engineer a new pathway in an organism; and Synthetic biology refers to the process of designing and developing new enzymes, biological pathways or even biological systems that do not previously exist in nature. ${ }^{5}$ Synthetic biology is considered to be the most ambitious approach to metabolic engineering.

\section{Current status of algal biotechnology}

The idea to genetically engineer the microalgal species to increase their valuable compounds is very attractive due to the merits mentioned earlier. Compared with higher plants, microalgae represent a much simpler system for genetic manipulations. The first stage is to screen the species from natural habitats and select the competent strains that can produce biofuel. The biomass productivity and lipid content of the selected strains are then optimized using techniques such as genetic manipulation.

Chlamydomonas reinhardtii is the most studied eukaryotic algae. It has a sequenced nuclear genome and well-built transgenic capabilities. ${ }^{6}$ Though $C$. reinhardtii is not an abundant lipid producer, it will definitely serve as a model for understanding the fundamentals of lipid synthesis and regulation. Metabolic engineering is used to increase the lipid production in microalgae. Several research studies have been carried out in algae $C$. reinhardtii ${ }^{7}$ in diatoms Thalassiosira pseudonana and Phaeodactylum tricornutum, ${ }^{8,9}$ in Haematococcus pluvialis $^{10}$ and in Nannochloropsis oceanic. ${ }^{11}$

These research studies have recognized various protein targets to enhance the production of lipid such as knocking down the lipases and nitrate reductase that are involved in lipid catabolism and inorganic nitrogen assimilation respectively, and overexpressing carrier proteins like 3-ketoacyl-ACP-synthase, and acyl-ACP thioesterase. Moreover, the efficiency of genetically modified organisms has to be examined in detail. Beacham et al. ${ }^{12}$ observed the changes that occurred during the gene expression and gene silencing in genetically modified Nannochloropsis salina. The nuclear genomes of unicellular 
green algae such as Chlamydomonas reinhardtii, Volvox carteri, and Chlorella variabilis), a red alga Cyanidioschizon merolae, and diatoms like Phaeodactylum tricornutum, Thalassiosira pseudonana, Fragilariopsis cylindrus have been either fully or partially sequenced.

Microalgal engineering research studies are now aiming to enhance photosynthesis and different metabolic pathways, altering the biosynthesis of lipid, and developing new pathways to produce the required products. With the continuous improvements and innovation in metabolic engineering understanding the metabolic pathways and lipid synthesis are feasible shortly.

\section{Can biotech achievements be commercialized?}

The aviation industry has pledged to achieve carbon-neutrality by 2020 . The use of sustainable fuel is a significant approach to achieve this target as it reduces the ecological footprint and boost the growth of aviation industry. Biofuels are organic as they are produced from plant based sources. Biofuels which do not compete with land, water and food crops and those that meet the jet fuel standards are referred to as sustainable aviation biofuels. The carbon emission levels over the life cycle are also less while using sustainable fuels when compared to fossil fuels. In addition these biofuel reduces the impact on biodiversity, does not contribute to conversion of natural ecosystem and have a positive socioeconomic impact. The collaboration among the biofuel manufacturers, airline companies, non-government organizations, and others are playing a significant role in commercializing sustainable jet fuels.

The Global aviation industry has a target especially to achieve carbon neutrality by 2020 and to reduce the carbon dioxide emission by $50 \%$ by 2050 compared to 2005 emission levels. ${ }^{13}$ Federal Aviation Authority ${ }^{14}$ has aimed to utilize one billion gallons of biofuel by 2018 , and Winchester et al. ${ }^{15}$ reported that jet fuel can qualify under both the EU renewable energy directive and US renewable fuel standards. Major airlines started using biofuels after their certification by the American Society for Testing and Materials (ASTM) and started operating scheduled commercial flights that are partly powered by biofuels. The first flight partly powered by the biofuel derived from cooking oil was operated in 2011 by KLM Royal Dutch Airlines from Amsterdam to Paris which is a Boeing 737 aircraft. ${ }^{16}$ Lufthansa ${ }^{17}$ Airlines also conducted several trials over a period of six months with 1187 flights between Hamburg and Frankfurt using biofuels derived from a wide variety of animal and plant fats. ${ }^{17}$ Though these trials were successful due to the short-term cooperation between airlines, aircraft manufacturers, biofuel suppliers, and airports, the main challenge faced by the airlines remains the sufficient supply of biofuels.

Airlines started establishing partnerships with the biofuel manufacturers to overcome the challenges associated with supply and demand; Lanza Tech, a Swedish biofuel company, and Virgin Atlantic signed a partnership in 2012. ${ }^{18}$ Another example of partnership for sustainable biofuel is when British Airways agreed to co-fund a project of Solena, a US firm, to convert 500,000 tonnes of domestic waste into 50,000 tonnes of aviation biofuel annually. ${ }^{19}$ Still, there are a lot of barriers in commercializing biofuel. Since 2009, United Airlines has been investing significantly in sustainable aviation biofuels. United Airlines operated the first passenger flight powered by advanced biofuels made from algae in 2011. It signed an agreement with AltAir Fuels for advanced aviation biofuels in 2013, and used it on flights out of its Los Angeles hub. Lane ${ }^{20}$ reported that United Airlines will purchase 15 million gallons of biofuel over a period of three years.
In 2015, United Airlines received the World Bio Markets (WBM) Award for Excellence in Advanced Biofuels..$^{21}$ As the biofuel is an emerging industry and plays a significant role in reducing the carbon footprint and protects the environment, United Airlines has invested about $\$ 30$ million in Fulcrum BioEnergy, Inc., which is one of the most successful the commercial biofuel producers in the US. This is considered to be a smart move as biofuels have the potential to protect an investor against increases in future oil prices. This agreement with Fulcrum will provide an opportunity to United Airlines to purchase a minimum of 90 million gallons of biofuel/year for at least ten years at a competitive cost. This will reduce its operational cost significantly. ${ }^{22}$

\section{Conclusion}

The technological advancements has brought about a lot of changes in algal biotechnology. It has provided the ability to select and breed the best strains, the ability to monitor and control system inputs, the ability to convert more biomass to fuel, possibility to harvest easily and extract more oil in a better way. Still commercializing algal biofuel requires a lot of effort and collaboration among the stakeholders. The current demand for renewable fuels especially in the transportation sector has made it necessary to develop a wide range of biofuel resources that are sustainable. The continued development of biotechnological and bioengineering methods to enhance the production of microalgae and extraction of oil from algae is one of the best solutions for the aviation industry to grow towards a sustainable and green future.

\section{Acknowledgement}

None.

\section{Conflict of interest}

The author declares that there is no conflict of interest.

\section{References}

1. Nair S, Paulose H. Emergence of green business models: The case of algae biofuel for aviation. Energy Policy. 2014;65:175-184.

2. Köhler J, Walz R, Marscheder-Weidermann, et al. Lead markets in $2^{\text {nd }}$ generation biofuels for aviation: A comparison of Germany, Brazil and the USA. Environmental Innovation and Societal Transitions. 2014;10:59-76.

3. May HZ, Yan Ling L, Rajee O, et al. Biofuel from microalgae-A review on the current status and future trends. International Journal of Advanced Biotechnology and Research. 2013;4(3):329-341.

4. Rajee O, Fabian KQ, Shen LJ, et al. Potential and Technological Advancements of Biofuels. International Journal of Advanced Scientific and Technical Research. 2014;4(4):12-29.

5. Glass D. Prospects for the Use of Genetic Engineering in Biofuel Production. Proceedings of the Energy: Utility and Environment Conference (EUEC); 2010 Feb.

6. Jinkerson RE, Jonikas MC. Molecular techniques to interrogate and edit the Chlamydomonas nuclear genome. Plant J. 2015;82(3):393-412.

7. Blatti JL, Beld J, Behnke CA, et al. Manipulating fatty acid biosynthesis in microalgae for biofuel through protein-protein interactions. PLOS One. 2012;7(9):e42949.

8. Levitan O, Dinamarca J, Zelzion E, et al. An RNAi knock-down of nitrate reductase enhances lipid biosynthesis in the diatom Phaeodactylum tricornutum. Plant J. 2015;84(5):963-973. 
9. Manandhar-Shrestha K, Hildebrand M. Characterization and manipulation of a DGAT2 from the diatom Thalassiosira pseudonana: Improved TAG accumulation without detriment to growth, and implications for chloroplast TAG accumulation. Algal Research. 2015;12:239-248.

10. Lei A, Chen H, Shen G, et al. Expression of fatty acid synthesis genes and fatty acid accumulation in Haematococcus pluvialis under different stressors. Biotechnol Biofuels. 2012;5(1):18.

11. Kaye Y, Grundman O, Leu S, et al. Metabolic engineering toward enhanced LC-PUFA biosynthesis in Nannochloropsis oceanica: Overexpression of endogenous $\Delta 12$ desaturase driven by stress-inducible promoter leads to enhanced deposition of polyunsaturated fatty acids in TAG. Algal Research. 2015;11:387-398.

12. Tracey A Beacham, Sohail T Ali. Growth dependent silencing and resetting of DGA1 transgene in Nannochloropsis salina. Algal Research. 2016;14:65-71.

13. International Air Transport Association. A global approach to reducing aviation emissions. Canada; 2009.

14. Federal Aviation Authority. FAA Destination 2025. Washington, DC: Government Printing Office; 2011.
15. Winchester N, McConnachie D, Wollersheim C, et al. Market cost of renewable jet fuel adoption in the United States. [A Partner Project 31 Report]. The Partnership for AiR Transportation Noise and Emissions Reduction Massac husetts Institute of Technology, Partner MIT, USA; 2013.

16. KLM. Sustainable Biofuels-Road to sustainable biofuels. [Press release]: Dutch; 2012.

17. Practical trial of biosynthetic fuel at Lufthansa successful. [Press release]: Lufthansa news, Australia; 2012.

18. Enviro Aero. Aviation biofuel flight tests. [Press release]: Switzerland; 2012.

19. British Airways. Solena- one destination. [Press release]: UK; 2013.

20. Jim Lane. Fly the (environmentally) friendly skies: Untied to commence wide scale aviation biofuel flights in 2014 [Press release]. USA; 2013.

21. Ecoskies. [Press release]: USA; 2015.

22. United Airlines Purchases Stake in Fulcrum Bio Energy with 30 million Investment [Press release]. USA; 2015. 